\title{
SEM, EDS and XRD Study of Heavy-Duty Asbestos Brake Pads
}

AI Martínez-Pérez ${ }^{1}$, G Luis-Raya ${ }^{1}$, G Villagomez-García ${ }^{1}$, EE Vera-Cárdenas ${ }^{2 *}$, R Cabrera $^{3}, \mathrm{M}$ Villanueva-Ibánez $^{1}$, M Moreno-Rios ${ }^{2}$ and EO Avila-Davila ${ }^{2}$

1. Universidad Politécnica de Pachuca, Carretera Pachuca-Ciudad Sahagún km 20, Ex-Hacienda de Santa Bárbara, Zempoala, Hgo., México.

2. Tecnológico Nacional de México/I. T. Pachuca, Carretera México-Pachuca Km. 87.5, Colonia Venta Prieta, Pachuca de Soto, Hgo., México.

3. Centro de Investigación en Ciencia Aplicada y Tecnología Avanzada Unidad Legaria, IPN, Ciudad de México, México.

* Corresponding author: eevc2000@hotmail.com

All light and heavy vehicles use brake pads, which are considered as important elements for the brake system along with the discs or drums. [1,2]. Most brake pads contain various ceramic or metallic materials and incorporate some type of asbestos fiber, which provides resistance to wear, structural stability and thermal stability. [3,4]. Currently the use of asbestos fibers has decreased due to its carcinogenic nature [5].

The samples were taken from a commercial brake pads, which were cut with a size of 10x10 mm. Tribological displacement tests were carried out to determine its resistance to wear, the conditions in dry and at room temperature of the tests were a load of $2.84 \mathrm{~N}$, frequency of $10 \mathrm{~Hz}, 18,000$ cycles and a sliding distance of $3 \mathrm{~mm}$, representing a distance traveled of $108000 \mathrm{~mm}$. The study carried out was based on SEM, EDS and XRD, these techniques of characterization allowed us to determine the composition and type of asbestos present in the brake pad.

In Figure 1 the fibrous morphology was observed, corresponding to the asbestos located inside the wear scars formed on the surface of the specimen by the displacement test. Figure 2 corresponds to the map SEM on the surface, showing the elements corresponding to the composition of the brake pad analyzed. In the XRD pattern shown in Figure 3, the presence of the phases of asbestos type chrysotile $\left(\mathrm{Mg}_{3} \mathrm{Si}_{2} \mathrm{O}_{5}(\mathrm{OH})_{4}, \mathrm{PDF}: 82-1838\right)$, silicon $\left(\mathrm{SiO}_{2}, \mathrm{PDF}: 74-0445\right)$ oxide and graphite (C, PDF: 74-2329) is verified.

\section{References:}

[1] UD Idris et al., J King Saud Univ - Eng Sci 27 (2015), p. 185. doi:10.1016/j.jksues.2013.06.006.

[2] P Arunmas, Bankok post. Thail Battles Rubber Price Rebound (2018), p. 32.

[3] X Qu et al., Materials. Polym Compos 25 (2004), p. 94. doi:10.1002/pc.20007.

[4] J Aveston, J Mater Sci 4 (1969), p. 625. doi:10.1007/BF00550118.

[5] JC Barrett, PQ Lamb and RW Wiseman, Environ Health Perspect 81 (1989), p. 81. doi:10.1289/ehp.898181. 


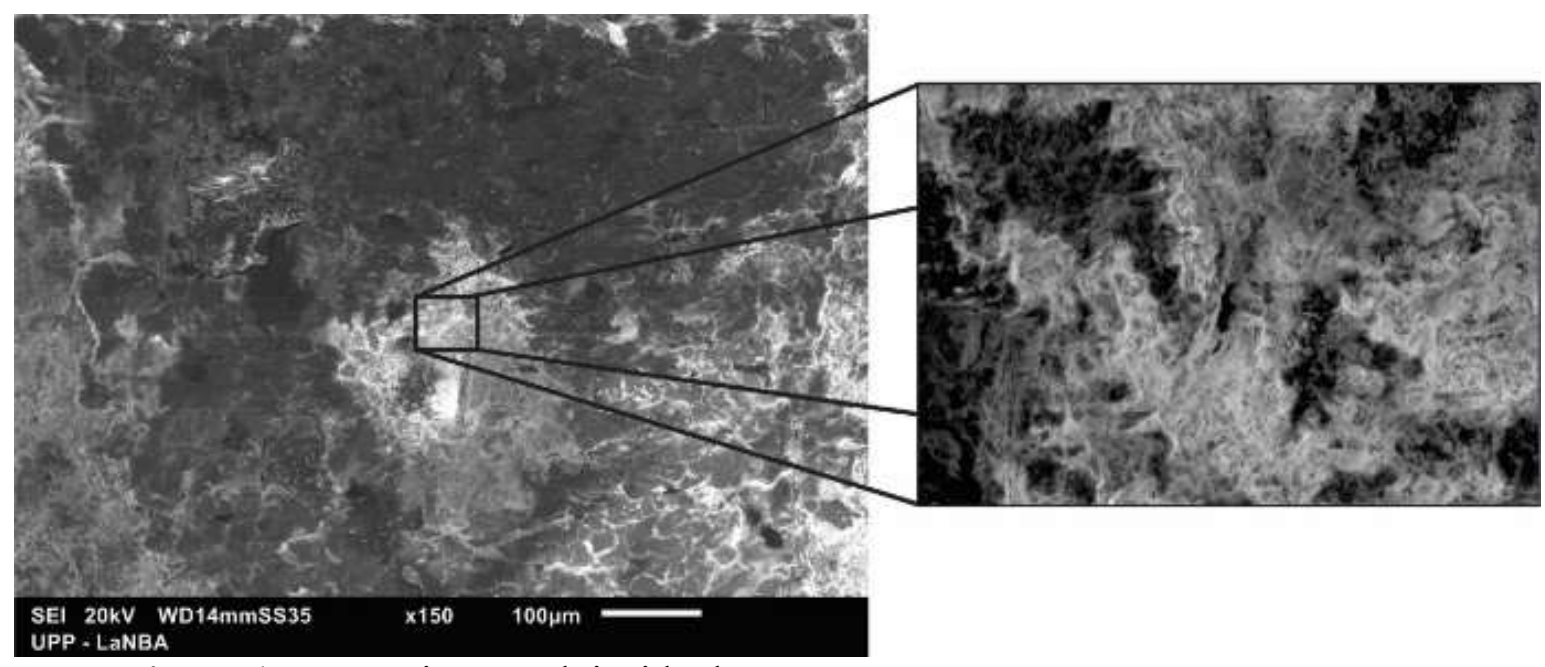

Figure 1. SEM micrograph inside the wear scars
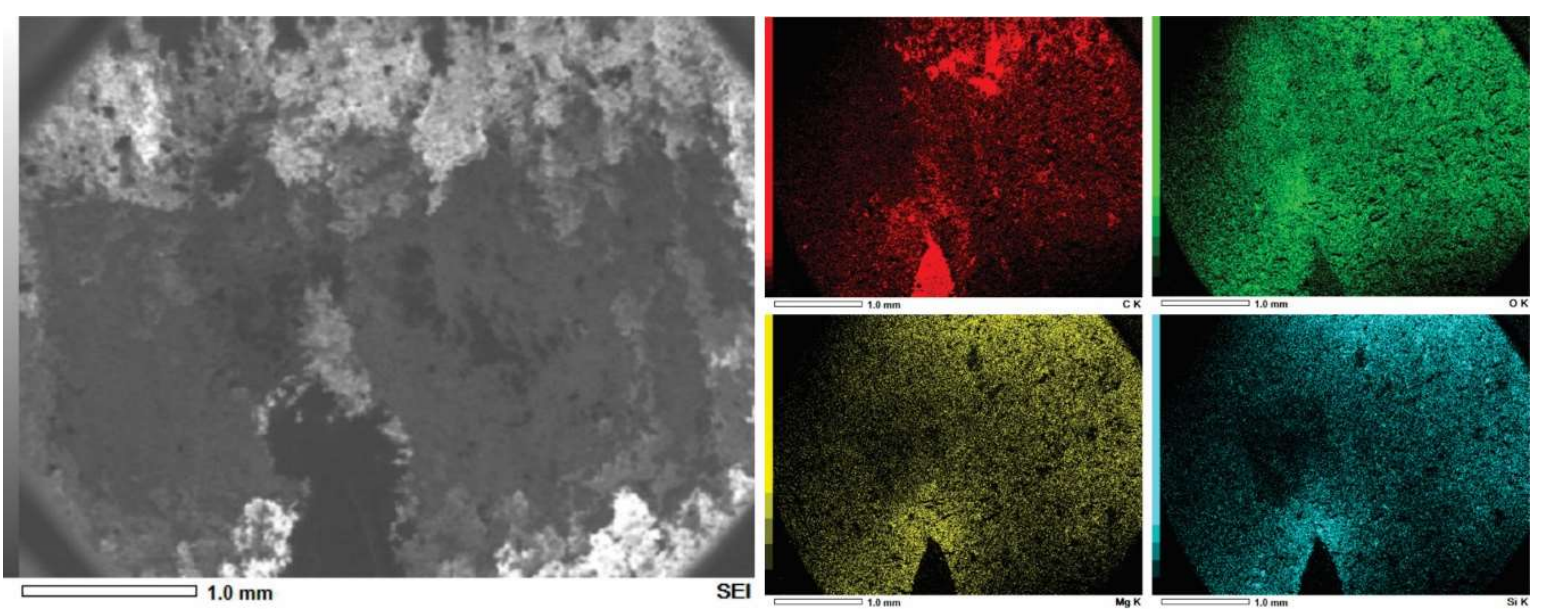

Figure 2. SEM micrograph maps

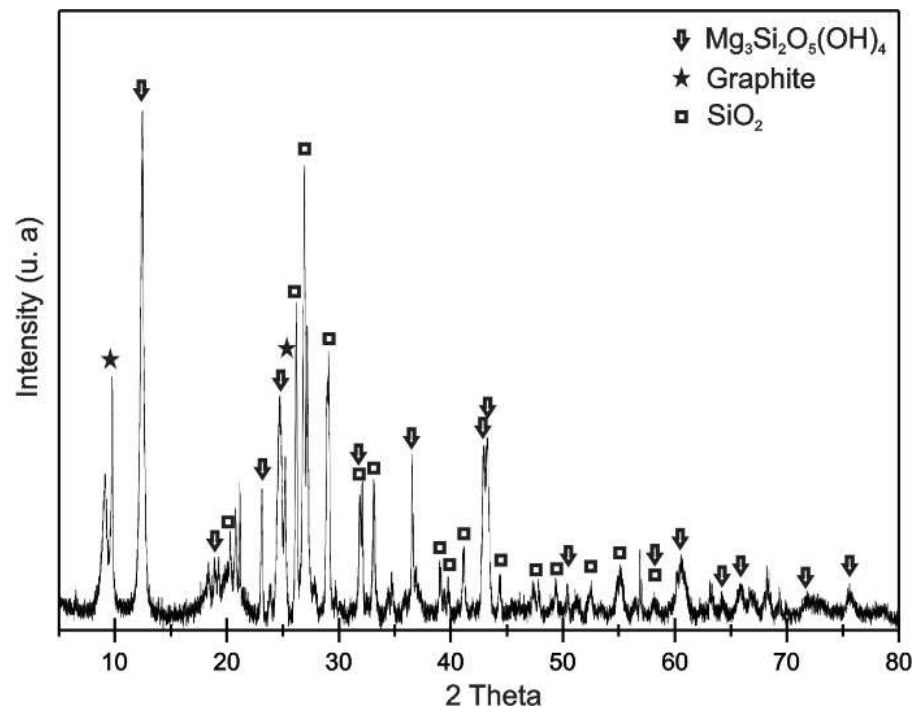

Figure 3. XRD diffraction pattern 